\title{
Recombinant expression of beak and feather disease virus capsid protein and assembly of virus-like particles in Nicotiana benthamiana
}

\author{
Guy L. Regnard ${ }^{1}$, Edward P. Rybicki ${ }^{1,2}$ and Inga I. Hitzeroth ${ }^{1 *}$
}

\begin{abstract}
Background: Beak and feather disease virus (BFDV) is an important disease causing agent affecting psittacines. BFDV is highly infectious and can present as acute, chronic or subclinical disease. The virus causes immunodeficiency and is often associated with secondary infections. No commercial vaccine is available and yields of recombinant BFDV capsid protein (CP) expressed in insect cells and bacteria are yet to be seen as commercially viable, although both systems produced BFDV CP that could successfully assemble into virus-like particles (VLPs). Plants as expression systems are increasingly becoming favourable for the production of region-specific and niche market products. The aim of this study was to investigate the formation and potential for purification of BFDV VLPs in Nicotiana benthamiana.
\end{abstract}

Methods: The BFDV CP was transiently expressed in N. benthamiana using an Agrobacterium-mediated system and plant expression vectors that included a bean yellow dwarf virus (BeYDV)-based replicating DNA vector. Plant-produced BFDV CP was detected using immunoblotting. VLPs were purified using sucrose cushion and $\mathrm{CsCl}$ density gradient centrifugation and visualised using transmission electron microscopy.

Results: In this study we demonstrate that the BFDV CP can be successfully expressed in N. benthamiana, albeit at relatively low yield. Using a purification strategy based on centrifugation we demonstrated that the expressed CP can self-assemble into VLPs that can be detected using electron microscopy. These plant-produced BFDV VLPs resemble those produced in established recombinant expression systems and infectious virions. It is possible that the VLPs are spontaneously incorporating amplicon DNA produced from the replicating BeYDV plant vector.

Conclusions: This is the first report of plant-made full-length BFDV CP assembling into VLPs. The putative pseudovirions could be used to further the efficacy of vaccines against BFDV.

Keywords: Plant-made pharmaceutical, Beak and feather disease virus, Virus-like particle, Circovirus, Subunit vaccine

\section{Background}

Beak and feather disease virus (BFDV; family Circoviridae, genus Circovirus) is one of the most common disease agents to infect psittacines [1]. The virus infects both wild and captive birds, and has been detected in at least $10 \%$ of psittacine species [2-4]. It is the causative agent of psittacine beak and feather disease (PBFD), which can present

\footnotetext{
*Correspondence: inga.hitzeroth@uct.ac.za

'Biopharming Research Unit, Department of Molecular and Cell Biology, Faculty of Science, University of Cape Town, Rondebosch 7701, Cape Town, South Africa

Full list of author information is available at the end of the article
}

in three forms. The acute form of the disease has a high mortality rate and is mainly seen in young and neonatal birds $[5,6]$. By far the most reported form of the disease is the chronic form, which primarily affects adult birds [7]. Symptoms of chronic disease are the characteristic beak and feather abnormalities associated with PBFD [8]. Birds that are infected with BFDV become immunocompromised, which is the primary cause of chronic infection and persistent excretion of the virus in diseased birds $[9,10]$. The third form of the disease is subclinical infection: this form presents the greatest risk for disease spread, as the 
infected birds continue to shed virus at low concentrations and show no symptoms of infection $[11,12]$.

A commercial vaccine for BFDV is currently unavailable, and treatment of PBFD is principally palliative and supportive [13-15]. Eradication of the disease is unlikely due to the prevalence of infection and the stability of the virus [16]. A vaccine against BFDV would therefore be desirable, especially due to the presence of subclinical infections that may complicate biocontrol efforts, and since the disease progression varies. The likelihood that a single-strain vaccine would be successful is high, due to the absence of obvious serotypes which indicates conservation of major epitopes between isolates: there is therefore a high probability of crossisolate protection $[17,18]$.

The virions of BFDV consist of icosahedral capsids, containing a 2-kb circular ssDNA genome that encodes two genes: these are the capsid gene $(c p)$, which produces the $\mathrm{CP}$, and the replication associated protein (rep), which produces Rep [19-21]. The literature reports the size of the virion to be between 14 and $20 \mathrm{~nm}$ in diameter, with the smallest reported size being $10 \mathrm{~nm}$ and the largest being $22 \mathrm{~nm}$ (Fig. 1). The range of virion sizes appeared to be independent of whether uranyl acetate or phosphotungstic acid was used during the staining procedure. A three dimensional structure determined by cryoelectron microscopy, however, gives a size of $20.5 \mathrm{~nm}$ [20]. The most recent analysis of particle size using electron and atomic force microscopy indicates that the $\mathrm{CP}$ can form two distinct assemblies with sizes of $10 \mathrm{~nm}$ and $17 \mathrm{~nm}$ and in addition this could possibly explain the range of

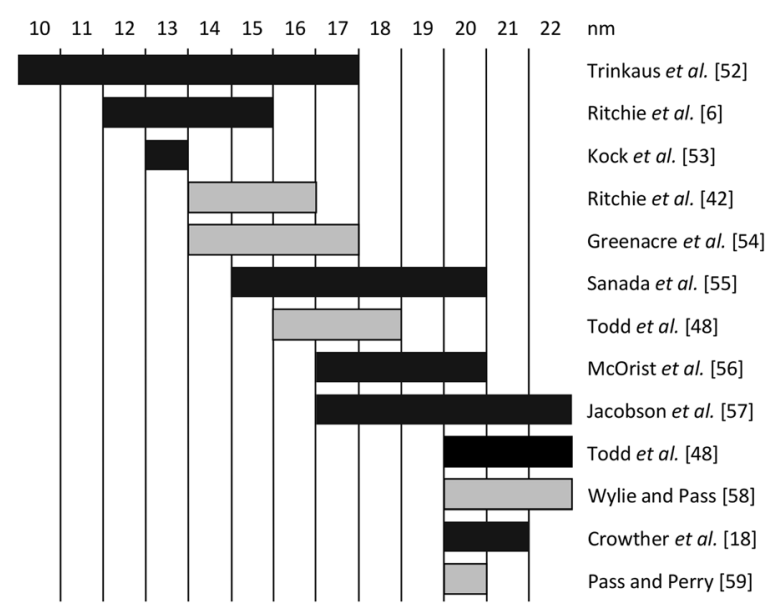

Fig. 1 Summary of the BFDV virion size as reported by various authors. Sizes were determined from electron micrographs of particles stained with either uranyl acetate (black) or phosphotungstic acid (grey) Trinkaus, et al. [59], Ritchie, et al. [8], Kock, et al. [60], Ritchie, et al. [49], Ritchie, et al. [49], Greenacre, et al. [61], Sanada, et al. [62], Todd, et al. [55], McOrist, et al. [63], Jacobson, et al. [64], Todd, et al. [55], Wylie and Pass [65], Crowther, et al. [20], Pass and Perry [66] reported values that have been described [22]. The virion is extremely stable in the environment, and horizontal transmission through ingestion of contaminated material is seen as the primary route of infection [16, 23]. The persistence of virus outside of the host and a dearth of available treatments have resulted in considerable research towards developing a vaccine against BFDV.

Initial vaccine research centred on inactivated virus vaccines derived from whole tissue of infected birds, purified from feathers or internal organs [12]. This was problematic, however, as production of purified virus was reliant on sourcing infected birds, which has ethical implications and can be severely limiting in terms of availability of harvestable tissue [10]. Furthermore, problems arising from incomplete inactivation of the purified virus have made an inactivated BFDV vaccine an unattractive option [24]. The virus has not as yet been propagated in tissue culture; therefore, the application of recombinant DNA technologies has been viewed as an alternative to infected whole tissue as a source of virus [25].

Recent work towards expression of recombinant BFDV $\mathrm{CP}$ shows great promise, with the CP having been successfully expressed using a number of expression platforms, including bacterial and yeast fermentation, insect cell culture and plants [15, 26-29]. Tissue culture technology has also been applied in the expression of other circovirus CPs, such as porcine circovirus (PCV) and goose circovirus (GoCV) [30, 31]. Use of recombinant PCV CP as a vaccine has been shown to result in a humoral response that can produce sterilising immunity that blocks effective virus infection of the host [32, 33]. Limited studies have been conducted on recombinant BFDV CP; however, Bonne, et al. [10] reported that vaccination with insect cell-produced CP failed to elicit sterilising immunity, and instead resulted in a decrease in viraemia, replication and virus shedding. This research indicates that recombinant BFDV CP could be used to effect a response in the psittacine immune system, but that further optimisation of the dosage would be required to improve the strength of the immune response.

One important area of focus for recombinant viral vaccine research has been in the production of virus-like particles (VLPs). These lack viral nucleic acids and are therefore non-infectious, while retaining the same structural characteristics of the infectious virion [34]. VLPs are highly immunogenic and stimulate both the humoral and cellular response pathways even in the absence of adjuvants, and have been successfully applied in humans both the hepatitis B and human papillomavirus vaccines are VLP-based - as well as in humans and poultry, against influenza [35-39]. The BFDV virion has a $T=1$ symmetry and is assembled from $60 \mathrm{CP}$ subunits that are arranged into 12 pentamer units [20]. The virion of circoviruses is comprised of repeats of a single protein, making it an 
attractive target for investigation of the production of VLPs - and these have in fact been demonstrated for $\mathrm{PCV}$ and demonstrated for bacterial and insect cellproduced BFDV CPs [22, 40-42].

Recombinant BFDV CP expressed in insect cell culture spontaneously assembles into particles ranging in size from 16 to $22 \mathrm{~nm}$ in diameter, which falls within the size range reported for infectious virions (10-22 nm in diameter) [41]. Attempts to produced BFDV VLPs using other recombinant systems have been mixed: for example, expression of the full-length BFDV CP using bacterial fermentation resulted in insoluble protein and low yields [15, 27]. Although the expression of a truncated version was successful in increasing yields, this may hinder the assembly of intact VLPs [27]. Sarker, et al. [29] have been able to successfully express the BFDV CP and form VLPs in E. coli with the yield an order of magnitude greater than reported in previous studies. Plant-based expression in $N$. benthamiana of BFDV CP by Duvenage, et al. [26] included a C-terminalfused 140 or 255 residue elastin-like polypeptide to improve protein yield and ease of purification. The fusion of the BFDV CP to the peptide tag would potentially affect the ability of the CP to assemble into VLPs, and assembly of the plant-expressed BFDV CP into VLPs was not assessed.

In summary, the development of a vaccine against BFDV has moved away from inactivated virus towards the recombinant expression and purification of BFDV CP. This has been shown to successfully produce a humoral response in vaccinated birds. Insect cell and bacterial fermentation-derived BFDV CP have been reported to assemble into VLPs, but this has yet to be shown for plant systems. The aim of this study, therefore, was to investigate the formation and potential for purification of BFDV VLPs in N. benthamiana, through the transient expression of the BFDV CP using, among others, a bean yellow dwarf virus (BeYDV)-based replicating DNA vector.

\section{Methods \\ Molecular cloning}

The BFDV $c p$ sequence from isolate BKS1ZA_84 (GenBank accession number GQ165756), isolated by Varsani, et al. [43] from a Budgerigar, was synthesised without codon optimisation by Geneart (Germany). The plant expression vectors used in this study were based on the pTRA binary Agrobacterium tumefaciens plant expression vector suite which was provided by Prof. Rainer Fischer of the Fraunhofer Institute for Molecular Biology and Applied Ecology in Germany [44]. The vector suite consists of three plant expression vectors targeting protein expression to different locations within the cell: pTRAc (cytoplasm), pTRAkc-ERH (endoplasmic reticulum retained) and pTRAkc-rbcs1-cTP (stromal compartment of the chloroplast) (Fig. 2). Removal of the SEKDEL-encoding sequence for pTRAkc-ERH produces pTRAkc-AH, which allows for the secretion of the recombinant protein to the apoplast. A fourth plant expression vector that was used for the expression of the BFDV CP was pRIC 3.0 (Fig. 2). This vector incorporates sequences of the single-stranded circular DNA genome of BeYDV that allow for vector replication in planta [45]. PCR amplification was used to modify the terminal ends of the BFDV $c p$ (Table 1), including a Cterminal histidine tag sequence and the introduction of restriction sites to generate a set of non-replicating and replicating constructs with different localisation signals (Fig. 3).

\section{A. tumefaciens-mediated transient expression}

The A. tumefaciens GV3101::pMP90RK cells were electroporated using 40-400 ng of recombinant plasmid as described by Maclean, et al. [44]. Recombinant clones were selected using agar plates containing kanamycin $(30 \mu \mathrm{g} / \mathrm{mL})$, rifampicin $(50 \mu \mathrm{g} / \mathrm{mL})$ and carbenicillin $(50 \mu \mathrm{g} / \mathrm{mL})$ and incubated at $27^{\circ} \mathrm{C}$.

For infiltration, recombinant A. tumefaciens GV3101:: pMP90RK were grown up overnight at $27^{\circ} \mathrm{C}$ with agitation in induction medium supplemented with kanamycin $(30 \mu \mathrm{g} / \mathrm{mL})$, rifampicin $(50 \mu \mathrm{g} / \mathrm{mL})$ and carbenicillin $(50 \mu \mathrm{g} / \mathrm{mL})$ [45]. The strain LBA4404 containing pBINNSs, provided by Marcel Prins from the Laboratory of Virology, Wageningen in the Netherlands, was supplemented with kanamycin $(30 \mu \mathrm{g} / \mathrm{mL})$, rifampicin $(50 \mu \mathrm{g} / \mathrm{mL})$ and $2 \mathrm{mM} \mathrm{MgSO}_{4}$. The addition of $\mathrm{MgSO}_{4}$ was to prevent cell clumping during incubation [44]. The NSs protein has been shown to suppress post-transcriptional gene silencing in plants, leading to an increase in transient protein expression [46]. Cells were harvested by centrifugation at $4000 \mathrm{~g}$ for $10 \mathrm{~min}$, and resuspended in infiltration medium [45]. The suspensions were diluted to the required absorbance $\left(\mathrm{OD}_{600}\right)$, for expression optimisation studies a range of $\mathrm{OD}_{600}$ values were tested, using an Ultrospec ${ }^{\mathrm{mm}} 10$ Cell density meter (Amersham Biosciences, United Kingdom) and incubated at $22^{\circ} \mathrm{C}$ for $2 \mathrm{~h}$. The A. tumefaciens GV3101::pMP90RK suspensions of each expression construct were co-infiltrated with strain LBA4404 containing pBIN-NSs into 6-week-old $N$. benthamiana plants by injecting the suspension into the abaxial spaces using a needleless $1 \mathrm{~mL}$ syringe. The plants were maintained in a greenhouse under a $16 \mathrm{~h}$ light and $8 \mathrm{~h}$ dark photoperiod at light intensity of $60-80 \mu \mathrm{E} / \mathrm{m}^{2} / \mathrm{s}$ and $22^{\circ} \mathrm{C}$.

Vacuum infiltration of A. tumefaciens into $N$. benthamiana was performed as described by Maclean, et al. [44], with the following modifications. The Agrobacterium strains were combined in infiltration medium for a final $\mathrm{OD}_{600}$ of 1.00 for strain GV3101::pMP90RK and 0.25 for strain LBA4404 making a total $\mathrm{OD}_{600}$ of 1.25 . The 6-week-old $N$. benthamiana plants were prepared for inversion into infiltration medium by sealing the base of the plant through the use of a $130 \times 130 \mathrm{~mm}$ acrylic 

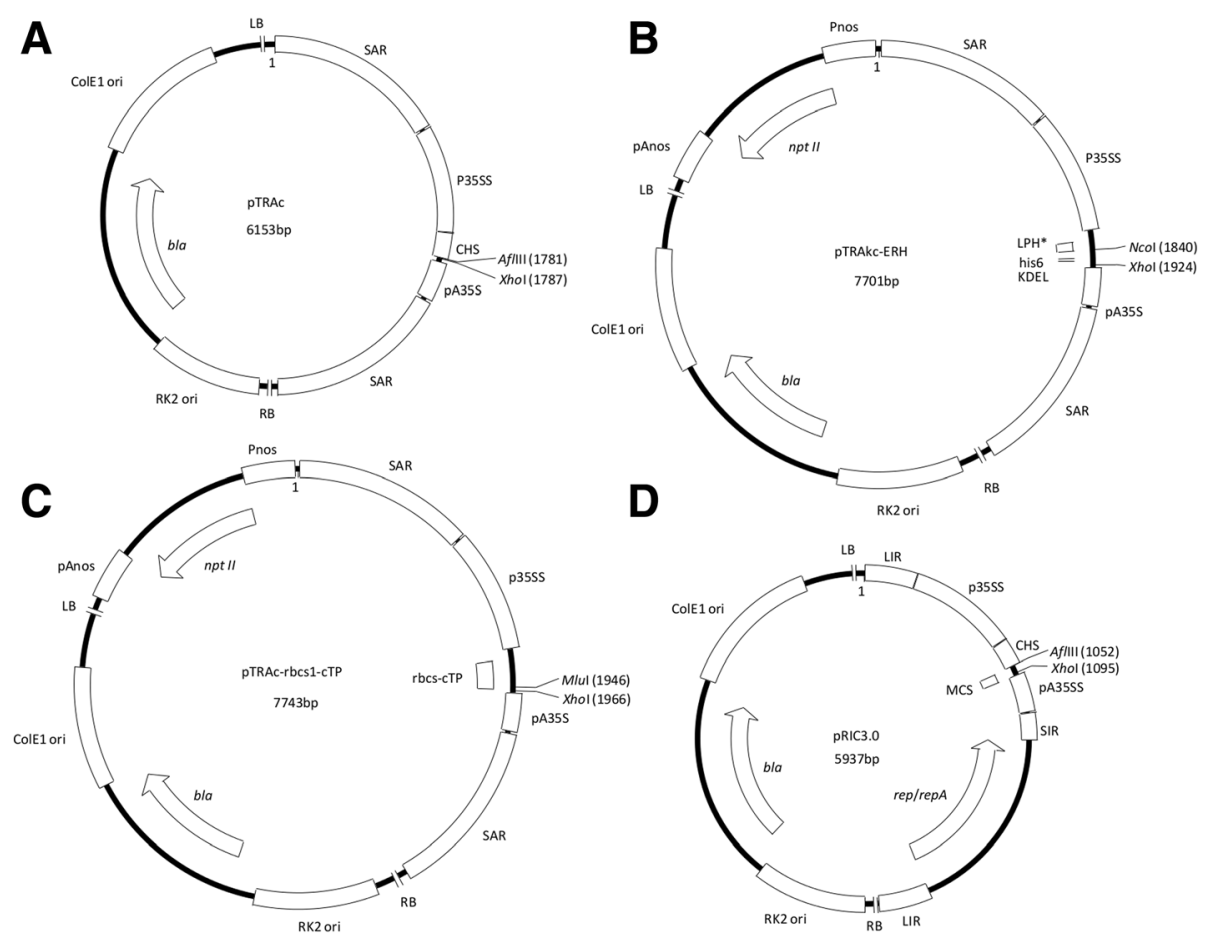

Fig. 2 Agrobacterium pTRA plant expression vectors: pTRAc (a), pTRAkc-ERH (b), pTRAkc-rbcs1-cTP (c) and pRIC 3.0 (d). LB and RB, left and right borders for T-DNA integration; SAR, scaffold attachment region of the tobacco Rb7 gene; P35SS, CaMV 35 S promoter with duplicated transcriptional enhancer; CHS, chalcone synthase 5' untranslated region; PA35S, CaMV 35 S polyadenylation signal; RK2 ori, origin of replication for A. tumefaciens; bla, ampicillin/carbenicillin-resistance bla gene; ColE1 ori, origin of replication for E. coli; LPH, signal peptide sequence from the murine mAb24 heavy chain; 6xHis, 6 His tag sequence; SEKDEL, ER-retention signal sequence; rbcs1-cTP, chloroplast-transit peptide sequence of a Rubisco small-subunit gene (rbcS1) from S. tuberosum; npt II, kanamycin-resistance npt II gene; Pnos and pAnos, promoter and polyadenylation signal of the nopaline synthase gene; LIR, BeYDV long intergenic region; rep/repA, BeYDV rep/repA gene; SIR, BeYDV short intergenic region

Table 1 Primers for PCR amplification used during molecular cloning

\begin{tabular}{|c|c|c|c|c|c|}
\hline \multicolumn{2}{|l|}{ Product } & \multicolumn{2}{|l|}{ Sense primer } & \multicolumn{2}{|l|}{ Antisense primer } \\
\hline Description & $\begin{array}{l}\text { Size } \\
\text { (bp) }\end{array}$ & Sequence $\left(5^{\prime}-3^{\prime}\right)$ & $\begin{array}{l}\text { Cloning } \\
\text { site }\end{array}$ & Sequence $\left(5^{\prime}-3^{\prime}\right)$ & $\begin{array}{l}\text { Cloning } \\
\text { site }\end{array}$ \\
\hline \multirow[t]{2}{*}{$\begin{array}{l}\text { BFDV BKS1ZA_84 cp } \\
6 x \mathrm{His}\end{array}$} & & GTAACGCGTTAGGTACATGTGGGGCACCTCTAAC & $\begin{array}{l}\text { Afllll/ } \\
\text { Mlul }\end{array}$ & GTGATGGTGATGCCCTTCAGTTCTGGGATTATTGG & \\
\hline & 796 & GTAACGCGTTAGGTACATGTGGGGCACCTCTAAC & $\begin{array}{l}\text { Afllll/ } \\
\text { Mlul }\end{array}$ & CATCTCGAGCTAGTGATGGTGATGGTGATGCCCTTC & Xhol \\
\hline $\begin{array}{l}\text { rbcs1-cTP BFDV } \\
\text { BKS1ZA_84 cp 6xHis }\end{array}$ & 959 & GGACCATGGCTTCCTCTGTTATTTCCTC & Ncol & CATCTCGAGCTAGTGATGGTGATGGTGATGCCCTTC & Xhol \\
\hline \multirow[t]{2}{*}{$\begin{array}{l}\text { BFDV BKS1ZA_84 cp } \\
6 x H \text { is SEKDEL }\end{array}$} & & GTAACGCGTTAGGTACATGTGGGGCACCTCTAAC & $\begin{array}{l}\text { Afllll/ } \\
\text { Mlul }\end{array}$ & CTCATCTTTCTCAGAGTGATGGTGATGGTGATGCC & \\
\hline & 814 & GTAACGCGTTAGGTACATGTGGGGCACCTCTAAC & $\begin{array}{l}\text { Afllll/ } \\
\text { Mlul }\end{array}$ & CCTCTCGAGCTAGAGCTCATCTTTCTCAGAGTGAT & Xhol \\
\hline $\begin{array}{l}\text { LPH BFDV BKS1ZA_84 } \\
\text { cp } 6 \text { xHis SEKDEL }\end{array}$ & 860 & GGACCATGGAGTGGAGCTGGATCTTC & Ncol & CCTCTCGAGCTAGAGCTCATCTITCTCAGAGTGAT & Xhol \\
\hline $\begin{array}{l}\text { LPH BFDV BKS1ZA_84 } \\
\text { cp } 6 \times \text { His }\end{array}$ & 840 & GGACCATGGAGTGGAGCTGGATCTTC & Ncol & CATCTCGAGCTAGTGATGGTGATGGTGATGCCCTTC & Xhol \\
\hline
\end{tabular}




\begin{tabular}{|c|c|c|c|c|c|c|c|c|}
\hline \multirow[b]{2}{*}{ pTRAc/pRIC 3.0} & \multicolumn{3}{|c|}{ Protein localisation } & \multicolumn{3}{|c|}{ Expression cassette } & \multirow{2}{*}{\multicolumn{2}{|c|}{ pA35S }} \\
\hline & Cytoplasm & P35SS & CHS & & BFDV $c p$ & 6xHis & & \\
\hline pTRAkc-AH/pRIC 3.0 & Apoplast & P35SS & CHS & LPH & $\mathrm{BFDV} c p$ & $6 \mathrm{xH}$ is & 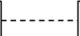 & pA35s \\
\hline pTRAkc-rbcs-cTP/pRIC 3.0 & 0 Chloroplast & P35SS & CHS & $\begin{array}{ll}\text { rbcs1-cTP } \\
\end{array}$ & BFDV $c p$ & 6xHis & & pA35S \\
\hline
\end{tabular}

sheet that contained a $10 \mathrm{~mm}$ channel to the centre to allow for the plant stem to be inserted (Fig. 4). This prevented soil from falling into the infiltration medium while the plant was inverted and leaves and stem submerged.

Plants were submerged into the bacterial suspension and subjected to a vacuum of $-90 \mathrm{kPa}$ for 5-10 min, with occasional agitation to release trapped air bubbles. The vacuum was released rapidly (approximately $10 \mathrm{kPa} / \mathrm{s}$ ). In addition, a recombinant expression control, using strain LBA4044 only, was vacuum infiltrated into plants. The plants were grown as described above.

The following controls were included: plant leaf tissue only, plant leaf tissue infiltrated with infiltration medium only, plant leaf tissue infiltrated with strain LBA4404 only, plant leaf tissue infiltrated with strain GV3101:: pMP90RK only and plant leaf tissue co-infiltrated with both strains.

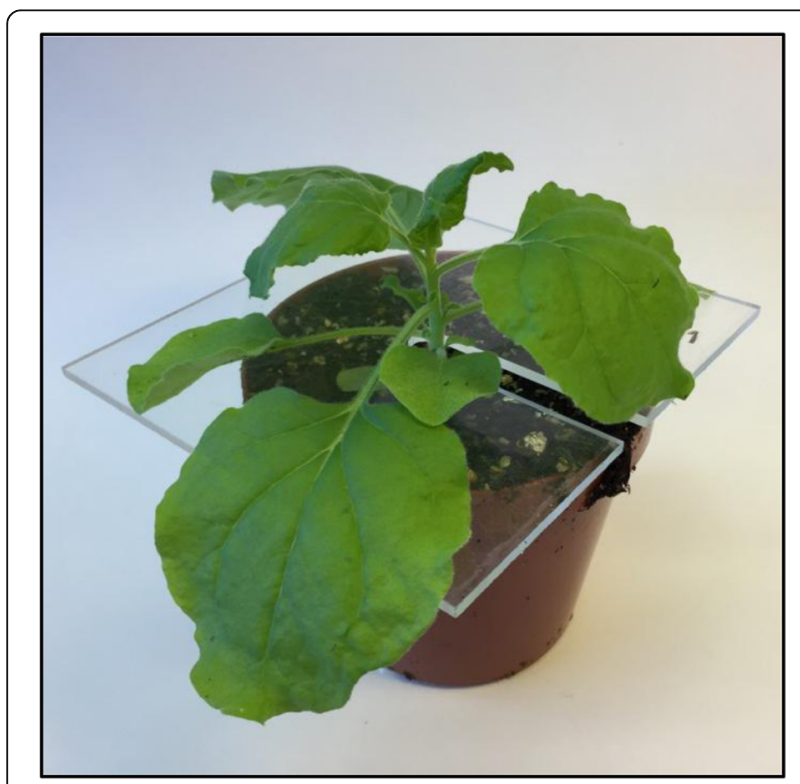

Fig. 4 Acrylic seal used to enclose soil during vacuum infiltration of $N$. benthamiana. The acrylic sheet $(130 \times 130 \mathrm{~mm})$ prevented soil from upturned plants from falling into the infiltration medium

\section{Protein extraction and western blot analysis}

For expression optimisation studies leaf discs were harvested at 1, 3, 5 and 7 days post infiltration (DPI). The plant material was prepared into a fine powder using a micro-pestle and liquid nitrogen. One hundred microlitres of extraction buffer (50 mM Tris, $100 \mathrm{mM} \mathrm{NaCl}, 10 \%$ glycerol and $1 \mathrm{mM}$ dithiothreitol at $\mathrm{pH}$ 7.5) per leaf disc was added and the leaf material was vortexed. The suspension of leaf tissue was clarified by centrifugation at $1500 \mathrm{~g}$ for $3 \mathrm{~min}$ and the supernatant representing the crude leaf extract was collected for further analysis. These were incubated at $90^{\circ} \mathrm{C}$ for $10 \mathrm{~min}$ in sample application buffer prepared for analysis by sodium dodecyl sulphatepolyacrylamide gel electrophoresis (SDS-PAGE) [47].

The proteins were resolved on 10\% SDS polyacrylamide gels and an equal volume of crude plant extract or equal amount of total soluble protein (TSP) were loaded into each lane. After gel electrophoresis the proteins were transferred onto nitrocellulose membranes at $15 \mathrm{~V}$ for $1 \mathrm{~h}$ using a Trans-blot ${ }^{\circ} \mathrm{SD}$ semi-dry transfer cell (Bio-Rad, CA, United States of America). The membranes were probed overnight at $4^{\circ} \mathrm{C}$ with 1:2000 antiHis tag mouse IgG antibody (AbD Serotec, NC, United States of America), and subsequently incubated in a 1:10,000 dilution of anti-mouse IgG (whole molecule) alkaline phosphatase antibody produced in goat affinity isolated antibody (Sigma-Aldrich). Membranes incubated in secondary antibody were washed four times with $1 \times$ PBST, with $15 \mathrm{~min}$ for each wash. Detection was performed with 5-bromo, 4-chloro, 3-indolylphosphate (BCIP) and nitroblue tetrazolium (NBT) phosphatase substrate (KPL, MD, United States of America).

Vacuum infiltrated plant leaves were harvested on day 3 post-infiltration and approximately $25 \mathrm{~g}$ of leaf tissue was used for the extraction of expressed recombinant BFDV CP. Leaves were rinsed in water to remove soil particulates and dried with paper towel to remove excess water, after which the plant material was ground into a fine powder in liquid nitrogen using a mortar and pestle. The plant material was then combined with PBS 
containing cOmplete ${ }^{\mathrm{Tm}}$ Mini, EDTA-free protease inhibitor (Roche) using a ratio of 1:2 $(w / v)$ of plant material to extraction buffer. PBS has previously been used as a buffer for the extraction of BFDV virions from whole tissue of diseased psittacines [48]. The mixture was then homogenised for $5 \mathrm{~min}$ at $10000 \mathrm{rpm}$ and $4^{\circ} \mathrm{C}$ using a $\mathrm{T} 25$ digital ULTRA-TURRAX ${ }^{\bullet}$ (IKA ${ }^{\circ}$ Works Inc., NC, United States of America). The homogenate was centrifuged at $4000 \mathrm{~g}$ for $10 \mathrm{~min}$ at $4^{\circ} \mathrm{C}$ using a JA-14 rotor (Beckman Coulter, CA, United States of America). The supernatant was then filtered through two layers of Miracloth (Merck, Germany) in preparation for sucrose cushion centrifugation.

\section{Sucrose cushion centrifugation}

Sucrose cushion centrifugation was based on the technique for purification PCV-2 capsid particles described by Wu, et al. [42]. A $40 \% w / v$ sucrose solution $(470.6 \mathrm{mg} / \mathrm{mL}$ of solution) was prepared in water and confirmed using a R5000 hand refractometer (Atago, Japan). A 2 mL 40\% sucrose cushion was prepared in $5 \mathrm{~mL}$ Ultra-Clear ${ }^{\text {Tix }}$ centrifugation tubes (Beckman Coulter) and layered with supernatant derived from the slow speed centrifugation step. The tubes were centrifuged in a $\mathrm{SW} 55 \mathrm{Ti}$ rotor (Beckman Coulter) at $40500 \mathrm{rpm}\left(\mathrm{RCF}_{\max } \approx 200,000 \mathrm{~g}\right.$ ) for $6 \mathrm{~h}$ at $4^{\circ} \mathrm{C}$. The pellet was resuspended in $500 \mu \mathrm{L}$ of PBS and further analysed by transmission electron microscopy (TEM).

\section{Transmission electron microscopy}

Analysis of BFDV CP particle assembly was done using TEM. Copper grids (mesh size 200) were made hydrophilic by glow discharging at $25 \mathrm{~mA}$ for $30 \mathrm{~s}$ using a Model 900 SmartSet Cold Stage Controller (Electron Microscopy Sciences, PA, United States of America). The grids were then placed on a 1:100 dilution of the samples for $5 \mathrm{~min}$ and then washed three times in sterile water. The grids were negatively stained on uranyl acetate for $10 \mathrm{~s}$ and again for a further $20 \mathrm{~s}$ and viewed using a Tecnai ${ }^{\text {Tw }}$ F20 Scanning Transmission Electron Microscope (FEI, OR, United States of America).

\section{$\mathrm{CsCl}$ density gradient centrifugation}

$\mathrm{CsCl}$ density gradient centrifugation was performed based on a protocol modified from Ritchie, et al. [49]. Leaves containing expressed recombinant BFDV CP were extracted as described above using a $50 \mathrm{mM}$ Tris at $\mathrm{pH} 7.6$ buffer at a ratio of 3:1 $(v / w)$ buffer to plant material. The sample together with a $5 \mathrm{~mL}$ sucrose cushion ( $45 \% \mathrm{w} / v$ sucrose solution; $541.1 \mathrm{mg} / \mathrm{mL}$ of solution) was centrifuged in a SW 32 Ti rotor (Beckman Coulter) at $32000 \mathrm{rpm}\left(\mathrm{RCF}_{\max } \approx 175,000 \mathrm{~g}\right)$ for $2 \mathrm{~h}$ at $4^{\circ} \mathrm{C}$. The resulting pellet was used for $\mathrm{CsCl}$ density gradient fractionation.
The pellets were resuspended in Tris buffer containing $\mathrm{CsCl}$ at a density of $1.406 \mathrm{~g} / \mathrm{cm}^{3}$. $\mathrm{CsCl}$ density was confirmed using a R5000 hand refractometer (Atago). The resuspended pellets were centrifuged using a SW $55 \mathrm{Ti}$ rotor (Beckman Coulter) at $48000 \mathrm{rpm}$ $\left(\mathrm{RCF}_{\max } \approx 280,000 \mathrm{~g}\right)$ for $20 \mathrm{~h}$ at $20^{\circ} \mathrm{C}$. The $\mathrm{CsCl}$ gradient was fractionated using a Foxy Jr. Fraction Collector (Teledyne Isco, NE, United States of America). The refractive index for each fraction was determined using the refractometer; $10 \mu \mathrm{L}$ of each fraction was spotted onto nitrocellulose membrane and western blot analysis was performed as described above. The BFDV CP present on the nitrocellulose membrane was then quantified using a Syngene Gene Genius imaging system and GeneTools software (Synoptics Inc., United Kingdom). In addition to quantifying the BFDV CP in each fraction, a ND-1000 Spectrophotometer (NanoDrop ${ }^{\circ}, \mathrm{DE}$, United States of America) was used to determine the TSP (Protein A280 module) and total DNA (Nucleic acid module).

Fractions containing the greatest concentration of BFDV CP were pooled and dialysed using dialysis tubing cellulose membrane (Sigma-Aldrich) against $50 \mathrm{mM}$ Tris at $\mathrm{pH}$ 7.6. Dialysed pooled fractions were analysed using western blotting as described above.

\section{Results}

Optimisation of BFDV CP expression in N. benthamiana

To determine the best conditions for expression, various densities of Agrobacterium suspensions were tested by plant syringe infiltration, and leaves were harvested on days $1,3,5$ and 7 . The optimum optical density for Agrobacterium suspension infiltration was determined to be 0.50 and 1.00 for the expression of BFDV CP and 0.25 for the expression of the silencing suppressor NSs, while the optimum day post-infiltration to harvest was determined by western blotting to be day 3 (data not shown). The effect of targeting the full-length BFDV CP to different organelles - chloroplast and ER, and secretion to the apoplast - was assessed together with gene amplification due to the replicating expression vector.

The CP was expressed by each plant expression vector (Fig. 5a). Additional proteins with higher molecular weights than the $\mathrm{CP}$ were detected in the SDS-PAG electropherograms. The cytoplasm was the most favourable location for accumulation, followed by the chloroplast and the ER, while accumulation of $\mathrm{CP}$ in the apoplast was the lowest. Gene amplification had a mixed effect on expression: accumulation in the cytoplasm and chloroplasts appeared to be improved; however, accumulation in the ER decreased, and there was no change when the $\mathrm{CP}$ was secreted to the apoplast. Overall, expression in the cytoplasm with gene amplification was determined to be the most favourable. 

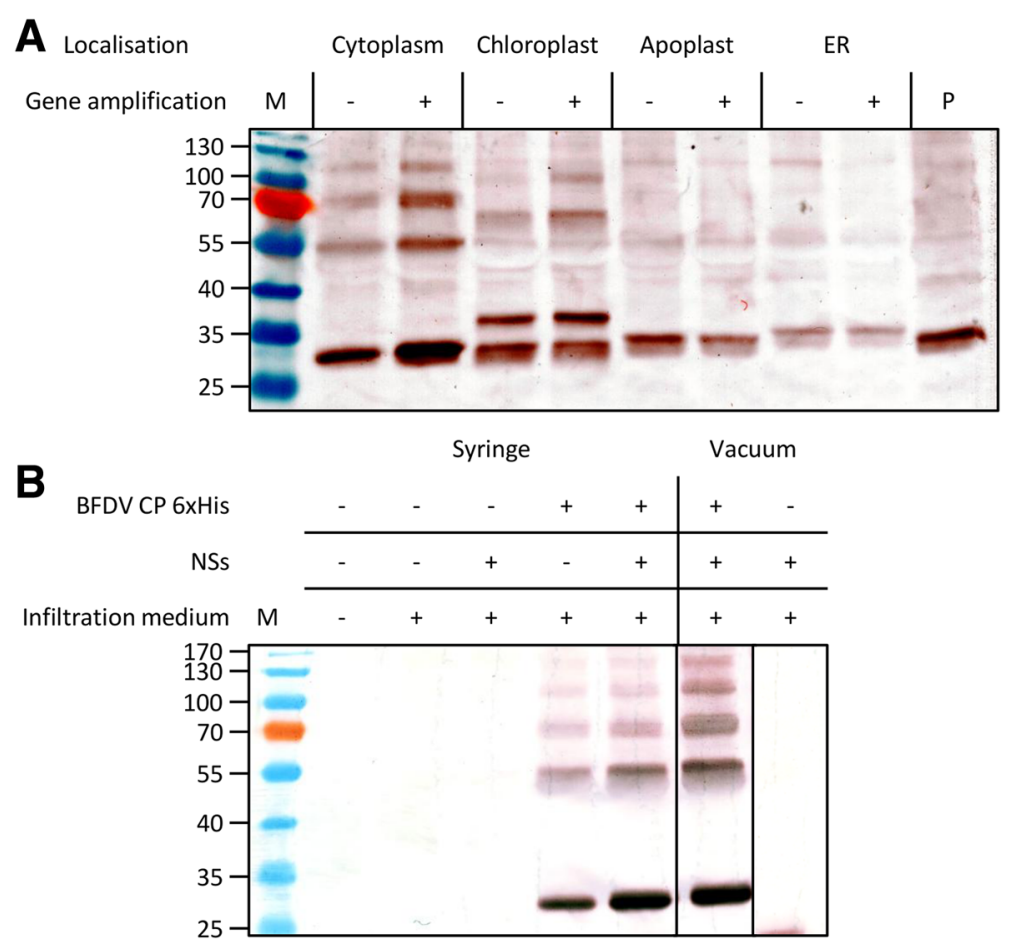

Fig. 5 Western blot analysis of BFDV CP expression. a Analysis of the effect of targeted BFDV CP localisation and BFDV $c p$ gene amplification on expression. Protein was extracted on day 3 from $N$. benthamiana leaves. Expression of the CP in the cytoplasm ( $30.1 \mathrm{kDa})$, the chloroplast $(36.0 \mathrm{kDa}), \mathrm{ER}(33.0 \mathrm{kDa})$ and secretion into the apoplast $(32.3 \mathrm{kDa})$. Expression in the presence $(+)$ or absence $(-)$ DNA amplification of the $c p$ was assessed in all cases. An equal amount of TSP was loaded into each lane and the CP was detected using anti-histidine antibody. M - prestained protein marker, P - positive control. b Analysis of BFDV CP expression comparing syringe versus vacuum infiltration of Agrobacterium. Negative controls were non-infiltrated plant leaves, leaves infiltrated with medium and NSs only. The presence $(+)$ or absence $(-)$ of each component is specified. TSP was extracted from leaf tissue harvested on day 4 post-infiltration. An equal volume of each sample was loaded into the lanes

Vacuum infiltration of $N$. benthamiana for the expression of BFDV CP

A comparison was made between the two methods of infiltration using the replicating pRIC 3.0 vector without a localisation signal (cytoplasm, Fig. 5b): the $30.1 \mathrm{kDa}$ CP was successfully expressed in $N$. benthamiana using both methods. The silencing suppressor evidently improved expression of the $\mathrm{CP}$, as an increase in band intensity was apparent for the CP co-expressed with NSs.

The pellet deriving from the sucrose cushion centrifugation of clarified plant extract was resuspended and analysed by TEM (Fig. 6). This analysis showed regular
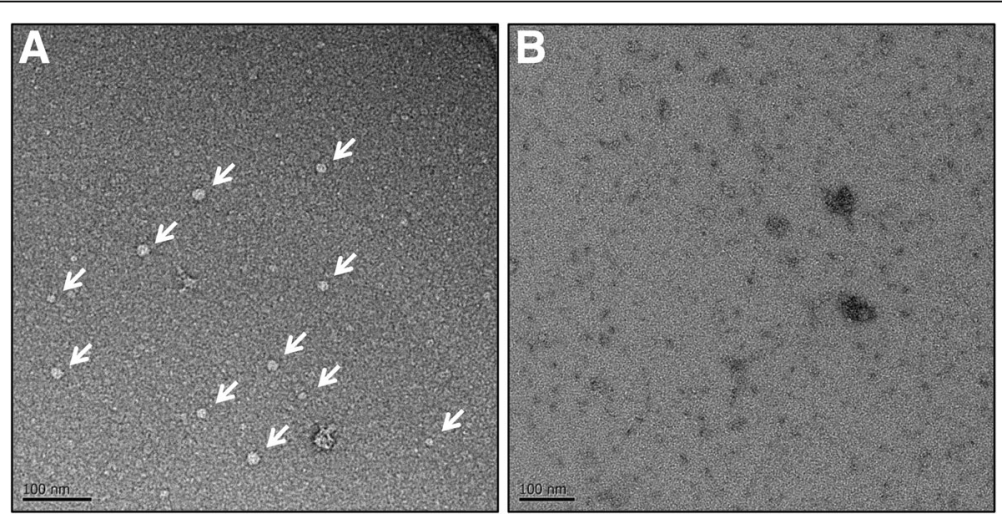

Fig. 6 Transmission electron micrographs of the partially purified BFDV VLPs (indicated by white arrows) after sucrose cushion centrifugation. a Resuspended pellet from leaf tissue expressing the BFDV CP with C-terminal histidine tag together with the silencing suppressor NSs. $\mathbf{b}$ Resuspended pellet from leaf tissue expressing only the silencing suppressor NSs which served as a negative control 
particles ranging between 13 and $23 \mathrm{~nm}$ in diameter in the pellet deriving from leaf tissue expressing the BFDV $\mathrm{CP}$ together with the silencing suppressor NSs (Fig. 6a). The predominant size detected was $\sim 17 \mathrm{~nm}$ in diameter. Analysis of the pellet from leaf tissue expressing the silencing suppressor NSs only showed nothing consistent with VLPs (Fig. 6b).

The BFDV CP/NSs co-expression and the NSs control pelleted material were further analysed by $\mathrm{CsCl}$ density gradient centrifugation. Fractions of the $\mathrm{CsCl}$ density gradients were collected for western blotting, and spectrophotometric analysis (Fig. 7): the fractions represent a $\mathrm{CsCl}$ density gradient that ranged from $1.29 \mathrm{~g} / \mathrm{cm}^{3}$ to $1.58 \mathrm{~g} / \mathrm{cm}^{3}$. Dot blot analysis using anti-histidine antibody on gradient fractions indicated a peak in staining intensity at fraction 6 for samples containing the BFDV $\mathrm{CP}$ co-expressed with the NSs silencing suppressor, and a shoulder peak in fraction 8 (Fig. 7a). These peaks were absent in the NSs-only samples. The peak fraction 6 for the $\mathrm{CP} / \mathrm{NSs}$ sample corresponded to a $\mathrm{CsCl}$ density of $1.38 \mathrm{~g} / \mathrm{cm}^{3}$. The shoulder peak (fraction 8 ) had a $\mathrm{CsCl}$ density of $1.34 \mathrm{~g} / \mathrm{cm}^{3}$. Fractions $5-7$ of for each density gradient were pooled, dialysed and analysed by Coomassie blue staining and western blotting of SDS-PAGE gels (Fig. 7b). The BFDV CP was undetectable when gels were stained with Coomassie blue (data not shown). However, bands corresponding to the histidine-tagged $30.1 \mathrm{kDa}$ $\mathrm{CP}$ and a protein of approximately $60 \mathrm{kDa}$ were detected in the $\mathrm{CP} / \mathrm{NSs}$ sample, while no histidine-tagged proteins were detected for the pooled fractions of the NSs silencing suppressor expressed on its own.

Further $\mathrm{CsCl}$ density gradient fraction analysis included spectrophotometry for protein $(280 \mathrm{~nm})$ and DNA $(260 \mathrm{~nm})$ concentrations. Three BFDV CP/NSs gradients were analysed (Fig. 8) by dot blot analysis using antihistidine antibody compared to $\mathrm{CsCl}$ density, and by TSP and total DNA concentration determination. The $\mathrm{CsCl}$ density gradient ranged from $1.29 \mathrm{~g} / \mathrm{cm}^{3}$ to $1.55 \mathrm{~g} / \mathrm{cm}^{3}$.
Again, a dot blot intensity peak was observed between fraction 5 and 6, corresponding to $\mathrm{CsCl}$ densities between $1.41 \mathrm{~g} / \mathrm{cm}^{3}$ and $1.44 \mathrm{~g} / \mathrm{cm}^{3}$ (Fig. 8a). The shoulder peak seen in the previous results was absent. A peak in TSP of $0.92 \mathrm{mg} / \mathrm{mL}$ was seen in fraction 5 (Fig. 8b). A second smaller peak for TSP was observed in fraction $9(\mathrm{CsCl}$ density of $1.34 \mathrm{~g} / \mathrm{cm}^{3}$ ), while a final peak was present at a density of $1.55 \mathrm{~g} / \mathrm{cm}^{3}$. Similar peaks were detected for total DNA concentration (Fig. 8c).

\section{Discussion}

The recombinant expression of BFDV CP in N. benthamiana was optimised by determining the optimum optical density of Agrobacterium at infiltration, the optimum day post infiltration for leaf harvesting, and the most favourable localisation of BFDV CP inside various cellular compartments (Fig. 5a). Localisation in the cytoplasm led to the greatest accumulation of $\mathrm{CP}$, on day $3 \mathrm{PI}$, when compared to chloroplast, apoplast and ER localisation. This corresponds well with what happens with the CP during viral infection, when $\mathrm{CP}$ expressed in the cytoplasm is transported into the nucleus by means of the nuclear localisation signal (NLS) encoded in its sequence [27]. While nuclear localisation was not investigated here, it is possible that presence of the NLS may negatively affect targeting to other cellular compartments: the NLSs are located in the $\mathrm{N}$-terminal region and could compete effectively with other $\mathrm{N}$-terminal signal tags. For example, chloroplast signal-tagging of the $\mathrm{CP}$ in this work resulted in the presence of an additional protein band of higher molecular weight: this could result from the CP being transported into the nucleus before the signal tag could be cleaved and CP deposited into the chloroplast. In order to confirm this, fluorescently labelled BFDV CP could be used together with an inverted epifluorescence microscope to trace the localisation of the protein in the plant cell as has been demonstrated using insect tissue culture by Heath, et al. [27]. Targeting the CP to the ER, with or

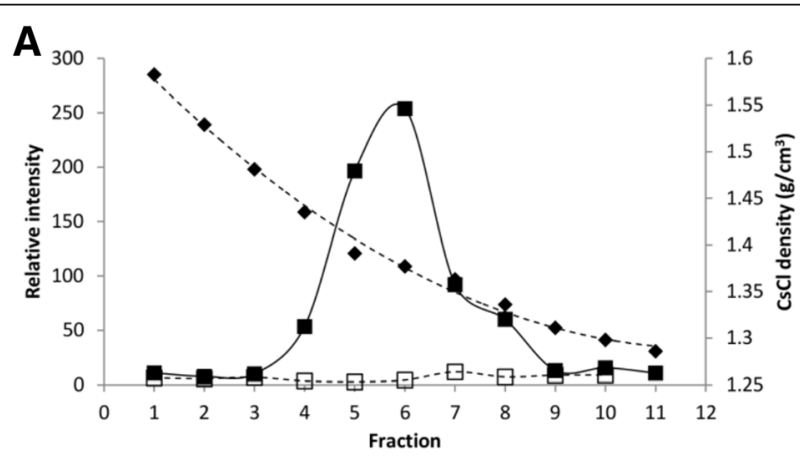

B

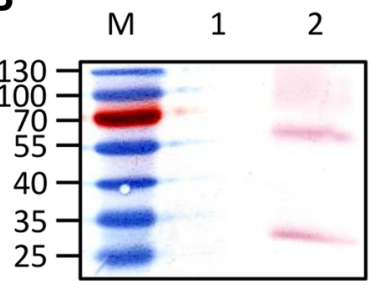

Fig. $7 \mathrm{CsCl}$ density gradient centrifugation profile of BFDV CP. a The CsCl density ( $\mathbf{*})$ and relative intensity of histidine tagged protein as determined

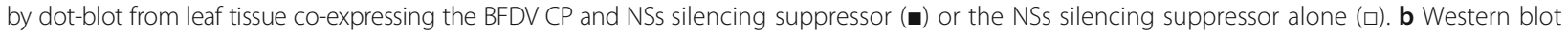
analysis of pooled fractions 5-7 after dialysis. M - Prestained protein marker, 1 - NSs control, 2 - BFDV CP and NSs. An equal volume of each sample was loaded into the lanes and the CP was detected using anti-histidine 

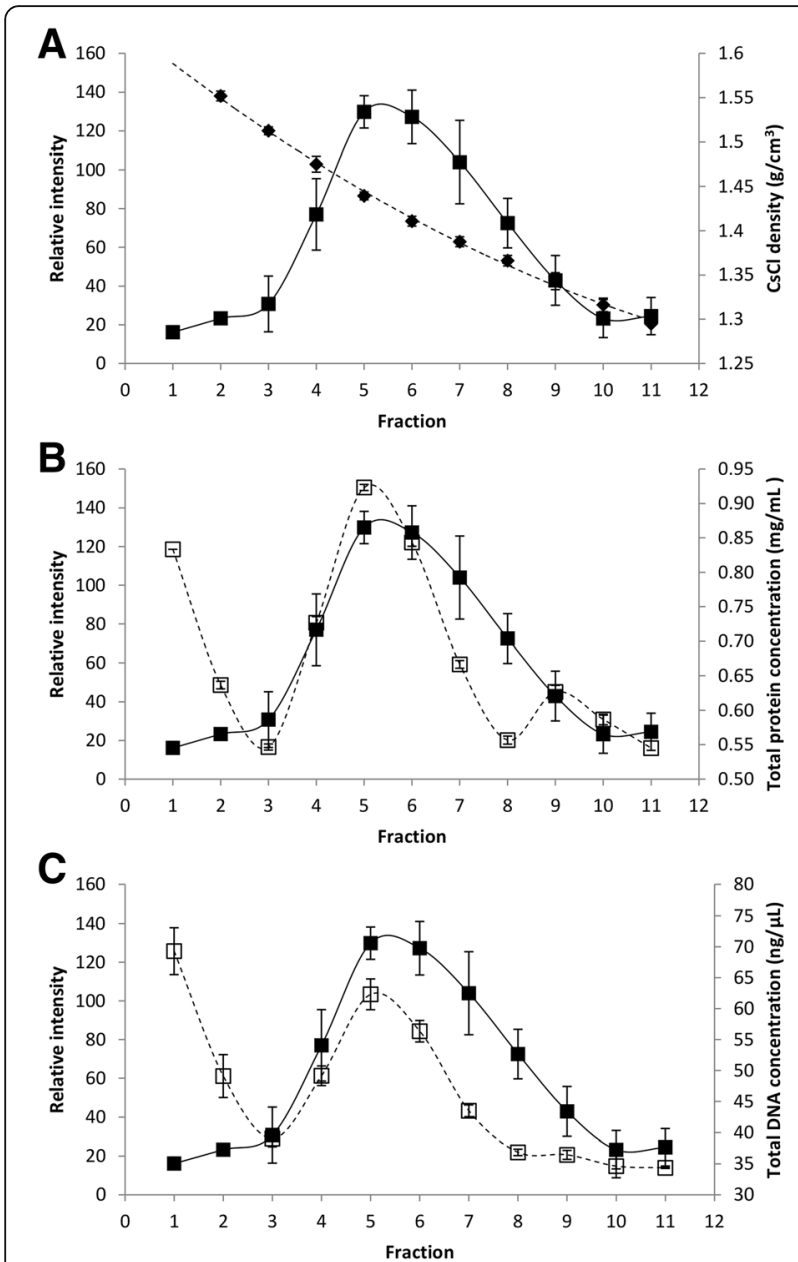

Fig. $8 \mathrm{CsCl}$ density gradient centrifugation profiles of BFDV CP, protein and DNA concentration. Comparison of relative intensity of histidine tagged protein as determined by dot-blot from leaf tissue co-expressing the BFDV CP and NSs silencing suppressor $(\mathbf{-})$ with a $\mathrm{CsCl}$ density ( $\mathbf{*}$ ), b TSP concentration ( $\square$ ) and $\mathbf{c}$ total DNA concentration ( $\square$ )

without inclusion of the ER retention SEKDEL sequence, resulted in a reduction in $\mathrm{CP}$ accumulation. It could be suggested that retention in the ER resulted in the CP being diverted to proteolytic vesicles, which would reduce the overall accumulation of $\mathrm{CP}$ in the plant cell. Alternatively, secretion to the apoplast could also result in degradation by abundant proteases in this compartment. While accumulation in the cytoplasm was satisfactory, an additional cellular compartment that could be investigated is the vacuole: Thomas and Walmsley [50] reported the accumulation of human epidermal growth factor was greatest when targeted to the vacuole, when compared to the ER and apoplastic space.

An increase in gene copy number had a variable effect on protein accumulation, dependent on the protein localisation. Gene amplification increased the overall protein accumulation in the cytoplasm and chloroplast, while a decrease/no effect in accumulation was observed in the apoplastic space and ER. As has been previously reported, an increase in gene copy number by means of gene amplification based on BeYDV rolling circle replication (RCR) could result in up to three orders of magnitude increase in gene copy number, with only a marginal increase in protein accumulation [45]. This could be as a result of diversion of cell resources away from transcription and protein translation to DNA replication. Analysis of mRNA transcription from a non-replicating plant expression vector has shown transcript levels to peak at three orders of magnitude higher [51]. Gene amplification would therefore probably compete with transcription for cell resources. A solution to this would be to control the level of gene amplification to much lower levels.

Although the various optimisations increased the expression level of BFDV CP, the protein was undetectable by SDS-PAGE when stained with Coomassie blue. Coomassie blue dyes can detect as few as $25 \mathrm{ng}$ per band for most proteins: this would indicate that the concentration of BFDV CP was below $625 \mathrm{ng} / \mathrm{mL}$. The BFDV CP would represent less than $0.00025 \%$ of TSP, and in terms of overall yield of BFDV CP per gram of fresh weight, this would be less than $5 \mathrm{mg} / \mathrm{kg}$. This is similar to recombinant expression levels seen for plant-produced HIV p17 / p24 of $5 \mathrm{mg} / \mathrm{kg}$ [45, 52], but far lower than the $>500 \mathrm{mg} / \mathrm{kg}$ achieved for HPV-16 L1 protein using the same vector systems [44, 45]. For plant-produced BFDV to be viable, yields approaching at least $50 \mathrm{mg} / \mathrm{kg}$ are required to commercial production, as has been reported for influenza VLPs [53].

Vacuum infiltration resulted in the same level of expression as when Agrobacterium suspensions are infiltrated using a needleless syringe, and as has previously been demonstrated, the co-expression of the silencing suppressor protein NSs results in an increase in BFDV $\mathrm{CP}$ accumulation (Fig. 5b). It could be suggested that the larger proteins detected in this study are potentially $\mathrm{CP}$ dimers, trimers and tetramers, and that these could potentially be precursors to the pentameric subunits described by Crowther, et al. [20].

TEM analysis of the sucrose cushion pellet revealed negatively stained particles that were circular and featureless (Fig. 6). This description perfectly fits the infectious BFDV particles seen by Crowther, et al. [20]. The plantproduced BFDV particles ranged between 13 and $23 \mathrm{~nm}$ in diameter, and were similar to putative BFDV VLPs produced in insect cell cultures, which ranged between 16 and $22 \mathrm{~nm}$ diameter [41]. The predominant diameter measured was approximately $17 \mathrm{~nm}$, which falls neatly within the 10-22 nm range reported for infectious virions, and is the same diameter as has been reported for the solved atomic structure of BFDV VLPs [22]. These values are similar to insect cell-produced PCV VLPs that 
averaged $20 \mathrm{~nm}$ in diameter, closely resembling the infectious PCV virion that consists of a $1.7-\mathrm{kb}$ genome encapsidated within a $20.5 \mathrm{~nm}$ non-enveloped capsid [20]. The addition of a histidine tag on the C-terminus, used for immunodetection, did not appear to negatively affect particle structure; however, the effect on the antigenicity of the protein would need to be addressed before immunogenicity studies.

Fractionation of $\mathrm{CsCl}$ gradients of the pellet produced during sucrose cushion centrifugation produced two peaks of BFDV CP. The major peak occurred at an approximate density of $1.38 \mathrm{~g} / \mathrm{cm}^{3}$, while a shoulder peak at $1.34 \mathrm{~g} / \mathrm{cm}^{3}$ was also detected (Fig. 7). A similar density of $1.365 \mathrm{~g} / \mathrm{cm}^{3}$ has been reported for PCV VLPs produced in Tn5 insect cells [54]. The higher observed density could also be the result of the presence of the C-terminal $6 x \mathrm{His}$ tag. The absence of viral DNA has been seen to affect the density of the VLPs. Infectious BFDV virions purified using $\mathrm{CsCl}$ have a density ranging between 1.35$1.378 \mathrm{~g} / \mathrm{cm}^{3}$, while intact VLPs range between $1.215-$ $1.325 \mathrm{~g} / \mathrm{cm}^{3}[41,48,55]$. A similar decrease in density has been reported for PCV VLPs [40].

To further investigate the purification of BFDV VLPs spectrophotometric analysis of protein and DNA concentrations were performed. The $\mathrm{CsCl}$ gradient fractions from material made using the recombinant replicating geminivirus-derived vector revealed coincident peaks corresponding to the protein and DNA (Fig. 8). This suggests that the BFDV CP could be packaging singlestranded amplicon DNA, as the viruses have very similar replication cycles. It could be that the major peak represents VLPs containing plant expression vector replicon DNA generated from RCR, and the shoulder peak could represent empty VLPs. Considering the BeYDV replicon is approximately $3.3-\mathrm{kb}$ it is questionable whether it could be successfully packaged by the BFDV CP. A BeYDV replicon that was similar in size to the 2-kb BFDV genome would be more suitable for encapsidation. Plant viral CPs have been shown to effectively and spontaneously package nucleic acids of mammalian viruses [56]. These pseudovirions have then been shown to release their nucleic acids into the cytoplasm of mammalian cells. This technology has also been used successfully using a plant-produced bamboo mosaic virus particles containing infectious bursal disease virus antigens for the immunisation of chickens [57]. Plant-produced CP derived from circoviruses could similarly be used to package nucleic acids that have been replicated in planta using the BeYDV replication system. These pseudovirions could then potentially be used to create a potent vaccine capable of eliciting a strong humoral and cellular response in the target host. This has previously been demonstrated in our group for plant-made human papillomavirus pseudovirions used in neutralisations assays [58].

\section{Conclusions}

In conclusion, BFDV CP has been shown to be successfully expressed in $N$. benthamiana via syringe or via vacuum infiltration. It has also been shown to self-assemble into VLPs even when fused with a C-terminal histidine tag that can be detected using electron microscopy and purified using $\mathrm{CsCl}$ centrifugation. These plantproduced BFDV VLPs resemble those produced in insect cells and infectious virions; however the yield was low, as the $\mathrm{CP}$ was undetectable when stained with Coomassie. The detection of VLPs in plants allows for refinement of the purification method, possibly by incorporating knowledge of the sedimentation coefficient determined for PCV and CAV to improve isolation by centrifugation. It is possible that the VLPs are spontaneously incorporating amplicon DNA produced from the replicating BeYDV plant vector. The putative pseudovirions could be used to further the efficacy of vaccines against BFDV.

\section{Abbreviations}

BCIP: 5-bromo, 4-chloro, 3-indolylphosphate; BeYDV: bean yellow dwarf virus; BFDV: beak and feather disease virus; $c p$ : capsid gene; CP: capsid protein; DPI: days post infiltration; GoCV: goose circovirus; NBT: nitroblue tetrazolium; PBFD: psittacine beak and feather disease; PCV: porcine circovirus; rep: replication associated protein; SDS-PAGE: sodium dodecyl sulphate-polyacrylamide gel electrophoresis; TSP: total soluble protein; VLPS: virus-like particles

\section{Acknowledgements}

The authors would like to thank Prof. Rainer Fischer of the Fraunhofer Institute for Molecular Biology and Applied Ecology in Germany for the pTRA vectors, Marcel Prins from the Laboratory of Virology, Wageningen in the Netherlands for providing pBIN-NSs and Dr. Mohammed Jaffer from the EM unit at UCT for help with the microscopy.

\section{Availability of data and material}

Not applicable.

\section{Funding}

This work was supported by funding from the South African National Research Foundation (NRF) and the University of Cape Town Research Committee (URC). The authors gratefully acknowledge the Poliomyelitis Research Foundation, the Harry Crossley Foundation as well as the NRF for student funding for Guy

Regnard. Opinions expressed and conclusions arrived at, are those of the authors and are not necessarily attributed to the NRF.

\section{Authors' contributions}

$\| H, G L R$ and EPR conceived and designed the experiments. GLR performed the experiments. $I H \mathrm{H}, \mathrm{GLR}$ and EPR analyzed the data. $I \| \mathrm{H}$ and EPR contributed reagents/materials/analysis tools. $I H$, GLR and EPR wrote the paper. All authors read and approved the final manuscript.

\section{Authors' information}

GLR is a postdoctoral researcher in the Biopharming Research Unit (BRU), $I \| \mathrm{H}$ is a Senior Research Officer and Deputy Director of BRU, EPR is Professor of Microbiology and Director of BRU in the Department of Molecular and Cell Biology at University of Cape Town.

Ethics approval and consent to participate Not applicable.

Consent for publication

Not applicable.

Competing interests

The authors declare that they have no competing interests. 


\section{Publisher's Note}

Springer Nature remains neutral with regard to jurisdictional claims in published maps and institutional affiliations.

\begin{abstract}
Author details
'Biopharming Research Unit, Department of Molecular and Cell Biology, Faculty of Science, University of Cape Town, Rondebosch 7701, Cape Town South Africa. ${ }^{2}$ Institute of Infectious Disease and Molecular Medicine, Faculty of Health Sciences, University of Cape Town, Observatory 7925, Cape Town, South Africa.
\end{abstract}

Received: 5 April 2017 Accepted: 5 September 2017 Published online: 11 September 2017

\section{References}

1. Fogell DJ, Martin RO, Groombridge JJ. Beak and feather disease virus in wild and captive parrots: an analysis of geographic and taxonomic distribution and methodological trends. Archives of virology. 2016;161:2059-74.

2. Ortiz-Catedral L, Mclnnes K, Hauber ME, Brunton DH. First report of beak and feather disease virus (BFDV) in wild Red-fronted Parakeets (Cyanoramphus novaezelandiae) in New Zealand. Emu. 2009;109:244-7.

3. Rahaus M, Wolff MH. Psittacine beak and feather disease: a first survey of the distribution of beak and feather disease virus inside the population of captive psittacine birds in Germany. Journal of Veterinary Medicine, Series B. 2003;50:368-71.

4. Harkins GW, Martin DP, Christoffels A, Varsani A. Towards inferring the global movement of beak and feather disease virus. Virology. 2014;450:24-33.

5. Shearer PL, Sharp M, Bonne N, Clark P, Raidal SR. A quantitative, real-time polymerase chain reaction assay for beak and feather disease virus. J Virol Methods. 2009;159:98-104.

6. Ha H, Anderson I, Alley M, Springett B, Gartrell B. The prevalence of beak and feather disease virus infection in wild populations of parrots and cockatoos in New Zealand. New Zealand Veterinary Journal. 2007;55:235-8.

7. Schoemaker N, Dorrestein G, Latimer K, Lumeij J, Kik M, Van Der Hage M, Campagnoli R. Severe leukopenia and liver necrosis in young African grey parrots (Psittacus erithacus erithacus) infected with psittacine circovirus. Avian diseases. 2000;44:470-8.

8. Ritchie BW, Niagro FD, Latimer KS, Lukert PD, Steffens WL, Rakich PM, Pritchard N. Ultrastructural, protein composition, and antigenic comparison of psittacine beak and feather disease virus purified from four genera of psittacine birds. Journal of Wildlife Diseases. 1990;26:196-203.

9. Raidal SR, McElnea CL, Cross GM. Seroprevalence of psittacine beak and feather disease in wild psittacine birds in New South Wales. Aust Vet J. 1993;70:137-9.

10. Bonne N, Shearer P, Sharp M, Clark P, Raidal S. Assessment of recombinant beak and feather disease virus capsid protein as a vaccine for psittacine beak and feather disease. Journal of General Virology. 2009;90:640-7.

11. Bert $\mathrm{E}$, Tomassone L, Peccati C, Navarrete M, Sola S. Detection of beak and feather disease virus (BFDV) and avian polyomavirus (APV) DNA in psittacine birds in Italy. Journal of Veterinary Medicine, Series B. 2005;52:64-8.

12. Raidal S, Cross G. Control by vaccination of psittacine beak and feather disease in a mixed flock of Agapornis spp. Aust Vet Practit. 1994;24:178-80.

13. Jergens AE, Brown TP, England TL. Psittacine Beak and Feather Disease Syndrome in a Cockatoo. Journal of the American Veterinary Medical Association. 1988;193:1292-4.

14. Rahaus M, Desloges N, Probst S, Loebbert B, Lantermann W, Wolff M. Detection of beak and feather disease virus DNA in embryonated eggs of psittacine birds. VETERINARNI MEDICINA-PRAHA. 2008;53:53.

15. Patterson El, Swarbrick C, Roman N, Forwood JK, Raidal SR. Differential expression of two isolates of beak and feather disease virus capsid protein in Escherichia coli. J Virol Methods. 2013;189:118-24.

16. Todd D. Avian circovirus diseases: lessons for the study of PMWS. Veterinary Microbiology. 2004;98:169-74.

17. Ritchie BW, Niagro FD, Latimer KS, Steffens WL, Pesti D, Campagnoli RP, Lukert PD. Antibody-Response to and Maternal Immunity from an Experimental Psittacine Beak and Feather Disease Vaccine. American Journal of Veterinary Research. 1992;53:1512-8.

18. Shearer PL, Sharp M, Bonne N, Clark P, Raidal SR. A blocking ELISA for the detection of antibodies to psittacine beak and feather disease virus (BFDV). J Virol Methods. 2009;158:136-40.
19. Bassami M, Ypelaar I, Berryman D, Wilcox G, Raidal S. Genetic diversity of beak and feather disease virus detected in psittacine species in Australia. Virology. 2001;279:392-400

20. Crowther R, Berriman J, Curran W, Allan G, Todd D. Comparison of the structures of three circoviruses: chicken anemia virus, porcine circovirus type 2, and beak and feather disease virus. Journal of virology. 2003;77:13,036-41.

21. Bassami M, Berryman D, Wilcox G, Raidal S. Psittacine beak and feather disease virus nucleotide sequence analysis and its relationship to porcine circovirus, plant circoviruses, and chicken anaemia virus. Virology. 1998;249:453-9.

22. Sarker S, Terrón MC, Khandokar Y, Aragão D, Hardy JM, Radjainia M, Jiménez-Zaragoza M, De Pablo PJ, Coulibaly F, Luque D. Structural insights into the assembly and regulation of distinct viral capsid complexes. Nature communications. 2016:7:1-7.

23. Davidson I, Artzi N, Shkoda I, Lublin A, Loeb E, Schat K. The contribution of feathers in the spread of chicken anemia virus. Virus Res. 2008;132:152-9.

24. Raidal SR, Firth GA, Cross GM. Vaccination and Challenge Studies with Psittacine Beak and Feather Disease Virus. Aust Vet J. 1993;70:437-41.

25. Shearer PL, Bonne N, Clark P, Sharp M, Raidal SR. Beak and feather disease virus infection in cockatiels (Nymphicus hollandicus). Avian Pathol. 2008;37:75-81.

26. Duvenage L, Hitzeroth II, Meyers AE, Rybicki EP. Expression in tobacco and purification of beak and feather disease virus capsid protein fused to elastin-like polypeptides. J Virol Methods. 2013;191:55-62.

27. Heath L, Williamson AL, Rybicki EP. The capsid protein of beak and feather disease virus binds to the viral DNA and is responsible for transporting the replication-associated protein into the nucleus. J Virol. 2006;80:7219-25.

28. Sariya L. Prompiram PSASP: Expression of Recombinant Capsid Protein of Psittacine Beak and Feather Disease Virus Capsid Protein using Pichia pastoris system. Journal of Applied Animal Science. 2014;7:35-44.

29. Sarker S, Ghorashi SA, Swarbrick CM, Khandokar YB, Himiari Z, Forwood JK, Raidal SR. An efficient approach for recombinant expression and purification of the viral capsid protein from beak and feather disease virus (BFDV) in Escherichia coli. Journal of virological methods. 2015;215:1-8.

30. Fachinger $V$, Bischoff $R$, Jedidia SB, Saalmuller A, Elbers $K$. The effect of vaccination against porcine circovirus type 2 in pigs suffering from porcine respiratory disease complex. Vaccine. 2008;26:1488-99.

31. Scott AN, Beckett A, Smyth JA, Ball NW, Palya V, Todd D. Serological diagnosis of goose circovirus infections. Avian Pathol. 2006;35:495-9.

32. Trible BR, Kerrigan M, Crossland N, Potter M, Faaberg K, Hesse R, Rowland RR. Antibody recognition of porcine circovirus type 2 capsid protein epitopes after vaccination, infection, and disease. Clinical and vaccine immunology. 2011;18:749-57.

33. Pérez-Martín E, Gómez-Sebastián S, Argilaguet JM, Sibila M, Fort M, Nofrarías M, Kurtz S, Escribano JM, Segalés J, Rodríguez F. Immunity conferred by an experimental vaccine based on the recombinant PCV2 Cap protein expressed in Trichoplusia ni-larvae. Vaccine. 2010;28:2340-9.

34. Santi L, Huang Z, Mason H. Virus-like particles production in green plants. Methods. 2006:40:66-76.

35. Scotti N, Rybicki EP. Virus-like particles produced in plants as potential vaccines. Expert review of vaccines. 2013;12(2):211-24.

36. Nerome K, Sugita S, Kuroda K, Hirose T, Matsuda S, Majima K, Kawasaki K, Shibata T, Poetri ON, Soejoedono RD. The large-scale production of an artificial influenza virus-like particle vaccine in silkworm pupae. Vaccine. 2015:33:117-25

37. Lenz P, Thompson CD, Day PM, Bacot SM, Lowy DR, Schiller JT. Interaction of papillomavirus virus-like particles with human myeloid antigenpresenting cells. Clinical immunology. 2003;106:231-7.

38. Tagliamonte M, Tornesello M, Buonaguro F, Buonaguro L. Virus-Like Particles. Micro-and Nanotechnology in Vaccine Development. 2016;205

39. Noad R, Roy P. Virus-like particles as immunogens. Trends in microbiology. 2003;11:438-44.

40. Nawagitgul P, Morozov I, Bolin SR, Harms PA, Sorden SD, Paul PS. Open reading frame 2 of porcine circovirus type 2 encodes a major capsid protein. Journal of General Virology. 2000;81:2281-7.

41. Stewart ME, Bonne N, Shearer P, Khalesi B, Sharp M, Raidal S. Baculovirus expression of beak and feather disease virus (BFDV) capsid protein capable of self-assembly and haemagglutination. J Virol Methods. 2007; 141:181-7.

42. Wu P-C, Lin W-L, Wu C-M, Chi J-N, Chien M-S, Huang C. Characterization of porcine circovirus type 2 (PCV2) capsid particle assembly and its application to virus-like particle vaccine development. Applied microbiology and biotechnology. 2012;95:1501-7. 
43. Varsani A, de Villiers GK, Regnard GL, Bragg RR, Kondiah K. Hitzeroth, II, Rybicki EP: A unique isolate of beak and feather disease virus isolated from budgerigars (Melopsittacus undulatus) in South Africa. Arch Virol. 2010;155:435-9.

44. Maclean J, Koekemoer M, Olivier A, Stewart D, Hitzeroth I, Rademacher T, Fischer R, Williamson A-L, Rybicki E. Optimization of human papillomavirus type 16 (HPV-16) L1 expression in plants: comparison of the suitability of different HPV-16 L1 gene variants and different cell-compartment localization. Journal of General Virology. 2007;88:1460-9.

45. Regnard GL, Halley-Stott RP, Tanzer FL, Hitzeroth II, Rybicki EP. High level protein expression in plants through the use of a novel autonomously replicating geminivirus shuttle vector. Plant Biotechnology Journal. 2010;8:38-46.

46. Takeda A, Sugiyama K, Nagano H, Mori M, Kaido M, Mise K, Tsuda S, Okuno T. Identification of a novel RNA silencing suppressor, NSs protein of Tomato spotted wilt virus. Febs Letters. 2002;532:75-9.

47. Sambrook J, Fritsch E, Maniatis T. Molecular cloning: A laboratory manual + Cold Spring Harbor. New York: Cold Spring Harbor Laboratory Press; 1989.

48. Raidal S, Cross G. The haemagglutination spectrum of psittacine beak and feather disease virus. Avian Pathology. 1994;23:621-30.

49. Ritchie BW, Niagro FD, Lukert PD, Steffens WL, Latimer KS. Characterization of a New Virus from Cockatoos with Psittacine Beak and Feather Disease. Virology. 1989;171:83-8.

50. Thomas DR, Walmsley AM. Improved expression of recombinant plantmade hEGF. Plant cell reports. 2014;33:1-14.

51. Kanagarajan S, Tolf C, Lundgren A, Waldenström J, Brodelius PE. Transient expression of hemagglutinin antigen from low pathogenic avian influenza A (H7N7) in Nicotiana benthamiana. PloS one. 2012;7:e33010.

52. Meyers A, Chakauya E, Shephard E, Tanzer FL, Maclean J, Lynch A, Williamson A-L, Rybicki EP. Expression of HIV-1 antigens in plants as potential subunit vaccines. BMC biotechnology. 2008;8:53.

53. D'Aoust MA, Lavoie PO, Couture MMJ, Trépanier S, Guay JM, Dargis M, Mongrand S, Landry N, Ward BJ, Vézina LP. Influenza virus-like particles produced by transient expression in Nicotiana benthamiana induce a protective immune response against a lethal viral challenge in mice. Plant Biotechnology Journal. 2008;6:930-40.

54. Liu L-J, Suzuki T, Tsunemitsu H, Kataoka M, Ngata N, Takeda N, Wakita T, Miyamura T, Li T-C. Efficient production of type 2 porcine circovirus-like particles by a recombinant baculovirus. Arch Virol. 2008;153:2291-5.

55. Todd D, Niagro F, Ritchie B, Curran W, Allan G, Lukert P, Latimer K, Steffens W III, McNulty M. Comparison of three animal viruses with circular singlestranded DNA genomes. Arch Virol. 1991;117:129-35.

56. Azizgolshani O, Garmann RF, Cadena-Nava R, Knobler CM, Gelbart WM. Reconstituted plant viral capsids can release genes to mammalian cells. Virology. 2013;441:12-7.

57. Chen T-H, Chen T-H, Hu C-C, Liao J-T, Lee C-W, Liao J-W, Lin M-Y, Liu H-J, Wang $M-Y$, Lin N-S. Induction of protective immunity in chickens immunized with plant-made chimeric Bamboo mosaic virus particles expressing very virulent Infectious bursal disease virus antigen. Virus research. 2012;166:109-15.

58. Lamprecht RL, Kennedy P, Huddy SM, Bethke S, Hendrikse M, Hitzeroth II, Rybicki EP. Production of Human papillomavirus pseudovirions in plants and their use in pseudovirion-based neutralisation assays in mammalian cells. Scientific reports. 2016;6:1-10.

59. Trinkaus K, Wenisch S, Leiser R, Gravendyck M, Kaleta EF. Psittacine beak and feather disease infected cells show a pattern of apoptosis in psittacine skin. Avian Pathol. 1998;27:555-61.

60. Kock N, Hangartner P, Lucke V. Variation in clinical disease and species susceptibility to psittacine beak and feather disease in Zimbabwean lovebirds. The Onderstepoort journal of veterinary research. 1993;60:159.

61. Greenacre CB, Latimer KS, Niagro FD, Campagnoli RP, Pesti D, Ritchie BW. Psittacine beak and feather disease in a scarlet macaw (Ara macao). Journal of the Association of Avian Veterinarians. 1992;6:95-8.

62. Sanada Y, Sanada N, Kubo M. Electron microscopical observations of psittacine beak and feather disease in an Umbrella cockatoo (Cacatua alba). The Journal of veterinary medical science/the Japanese Society of Veterinary Science. 1999;61:1063-5.

63. McOrist S, Black DG, Pass DA, Scott PC, Marshall J. Beak and feather dystrophy in wild sulphur-crested cockatoos (Cacatua galerita). Journal of Wildlife Diseases. 1984;20:120-4.
64. Jacobson ER, Clubb S, Simpson C, Walsh M, Lothrop CD, Gaskin J, Bauer J, Hines S, Kollias GV, Poulos P, Harrison G. Feather and Beak Dystrophy and Necrosis in Cockatoos - Clinicopathological Evaluations. Journal of the American Veterinary Medical Association. 1986;189:999-1005.

65. Wylie SL, Pass DA. Experimental reproduction of psittacine beak and feather disease/French Moult. Avian Pathol. 1987;16:269-81.

66. Pass DA, Perry RA. Psittacine Beak and Feather Disease - an Update. Australian Veterinary Practitioner. 1985;15:55-60.

\section{Submit your next manuscript to BioMed Central and we will help you at every step:}

- We accept pre-submission inquiries

- Our selector tool helps you to find the most relevant journal

- We provide round the clock customer support

- Convenient online submission

- Thorough peer review

- Inclusion in PubMed and all major indexing services

- Maximum visibility for your research

Submit your manuscript at www.biomedcentral.com/submit 